\title{
Temporal factors influencing the acquisition and maintenance of an autoshaped keypeck*
}

\author{
H. S. TERRACE. J. GIBBON, L. FARRELL, and M. D. BALDOCK \\ Columbia University, New York New York 10027
}

\begin{abstract}
Food-deprived pigeons were given brief meals of grain following the presentation of a lignt on a response key. Pecking the key had no consequence. Virtually all of the pigeons pecked the lighted key. The number of trials prior to the first peck varied inversely with the value of the mean interval between light onsets. Trials to criterion was a negative power function of the value of the intertrial interval. The addition of a second stimulus, never followed by food, retarded the acquisition of the keypeck, particularly at short intertrial intervals. During steady state performance, the value of two measures of response strength, rate and probability of responding, increased as a function of the duration of the intertrial interval.
\end{abstract}

Autoshaping refers to the conditioning of certain skeletal responses that result when the occurrence of a positive reinforcer is signaled by a salient stimulus. For example, when a food-deprived pigeon is exposed to a series of trials in which an illuminated response key signals a brief presentation of food. the pigeon will peck the key even though pecks are not a iecessary condition for food presentations (Browil \& Jenkins, 1968). Likewise, Peterson et al (1972) have autosilaped rats to press a retractable bar simply by inserting the bar in the experimental chamber prior to non-(response) contingent presentations of food. At present, it is not possible to specify a priori just which stimuli will prove effective in an autoshaping paradigm. In the case of pigeons, for example, the onsets of a small localized visual stimulus are effective, whereas tones nave thus far proven ineffective (cf. Hearst \& Jenkins, 1974).

Since its discovery by Brown and Jenkins (1968), a variety of psychologists have cited both the practical and the theoretical importance of autosnaping (e.g., Bolles, 1972; Segal, 1972; Seligman \& Hager, 1972). The value of autoshaping as a means of standardizing the acquisition procedure to a greater degree than is possible with the process of "shaping" can hardly be questioned. It is nevertheless apparent that the theoretical questions posed by this phenomenon are more significant than its practical advantages. One cannot use autoshaping to train keypecks and barpresses, the most widely studied examples of "arbitrary" operant responses, without questioning the validity of traditional distinctions between operant and classical conditioning. Not only have experiments on autoshaping shown that a nonautonomic response such as the pigeon's keypeck can be readily conditioned by a classical conditioning procedure, but they also question how the law of effect

*This research was supported in part by grants from the National Science Foundation (GB 30781) and from the National Institutes of Health (HD 00930). R eprints may be obtained from H. S. Terrace, Columbia University, Psychology Department, New York, New York 10027. can account for the maintenance of such responses. The demonstration that pigeons persist at pecking, even when the consequence of a peck is the omission of food (Williams \& Williams, 1969; Herrnstein \& Loveland, 1972), appears to contradict the law of effect. From these considerations alone, it should be clear that the phenomenon of autoshaping necessitates a rethinking of widely cited theoretical distinctions that have been drawn between the processes, as opposed to the procedures, of classical and instrumental conditioning.

One major obstacle to a reformulation of traditional two-factor learning theory is a paucity of systematic data on acquisition. The informality of nandsinaping procedures, as well as the rapidity with whicil such shaping takes place, provides little opportunity to collect information concerning the actual process of acquisition. For this reason, as well as the widespread assumption that "arbitrary" operants such as a keypeck and a barpress are ideal preparations for studying the effects of instrumental contingencies, empirical data on the acquisition of these responses has been much less plentiful than data on their maintenance.

The present experiments seek to obtain parametric data which would provide a basis for relating autoshaping to other basic conditioning phenomena. The variables we studied are the duration of the interval between stimulus presentations which signal food, and the presence of a second signal which is never followed by food.

\section{EXPERIMENT I}

\footnotetext{
Method

Subjects and Apparatus. The Ss were 72 male White Carneaux pigeons whose ages ranged from 6 months to 1 year. All of the Ss were experimentally naive. Each $S$ was maintained at $80 \%$ of its ad lib weight throughout its experimental history. The experiment was conducted in two identical operant-conditioning chambers of the type described by Ferster and Skinner (1957).

Procedure. All Ss were given a minimum of 10 hopper training
} 
trials. If the $\mathrm{E}$ who observed hopper training (via a video monitor) was not satisfied with the reliability of eating, a few additional trials were provided. In no case did the number of hopper presentations exceed 15 . Following hopper training, food was presented to each of 12 groups of food-deprived pigeons, according to the following procedure: A homogeneous field of green light (S1) was projected on the response key for 10 sec. Specifically, S1 was generated by IEE stimulus-display devices (Box 1: Model 10M 54 Q-1820B; Box 2: Model 10 452-Q44A), each of which projected the output of a $28-\mathrm{V}$ bulb (GE 1829) through a Wratten filter and onto the rear of the response key. At the offset of S1, the houselight was turned off, the lights above the food hopper were illuminated, and the hopper was raised. The houselight illuminated the chamber at all times during each session except during food presentations. The luminances of the houselight, the hopper lights, and S1 were, respectively: $1.6,0.1$, and $-1.2 \log \mathrm{fL}$.

Following the intertrial interval (ITI) the sequence, S1 followed by food, was presented again. The duration of the ITI was defined as the period that elapsed from the offset of reinforcement to the onset of the next S1. During the ITI, the key was dark. Pecks that occurred during the ITI and during the trial were counted separately 'but otherwise had no consequences. Each experimental session was terminated after 25 signaled food presentations.

The treatment of the experimental groups differed in various minor respects other than the value of the intertrial interval. These are summarized in the upper half of Table 1. In eacli case, the ITI values refer to the mean value of the (geometric) distribution of intervals. In Box 1 , ITI values were generated by a probability generator used in conjunction with a fixed timer. One-half second after the food presentation that terminated an S1 trial, the probability generator determined whether or not a new trial was to start immediately. If a trial was programmed, it ended again in reinforcement and $1 / 2 \mathrm{sec}$ later the probability generator was queried again. When no trial was programmed, $10.5 \mathrm{sec}$ elapsed before the probability generator was queried again, and so on, until a trial was programmed. This resulted in a geometric distribution of intertrial intervals. The minimum duration of the interval between the end of reinforcement and the onset of the next trial was $0.5 \mathrm{sec}$. The approximate maximum values of this interval are listed in Table 1. The rationale for generating ITI values in this manner is irrelevant to the purpose of the present experiment.

In Box 2, ITI values were generated by a variable interval program and a family of tapes constructed by the procedure developed by Catania and Reynolds (1968). Each VI tape consisted of 25 intervals with approximately geometric distributions (though not necessarily at multiples of $10.5 \mathrm{sec}$, as in Box 1). The durations of the minimum and of the maximum intervals generated by the probability generator (Box 1) were, respectively, shorter and longer than the durations of the minimum and maximum intervals generated by the VI tapes. A possible consequence of this difference is discussed below. Following the first session in which a peck occurred during an S1 trial, the course of acquisition to asymptotic response levels was observed for most of our groups over a 10 -session period. In some cases, not all of the Ss of a particular group were run for all 10 maintenance sessions. This is indicated in the upper portion of Table 1 .

\section{Results}

Acquisition. Three criteria were used to evaluate tine acquisition of the keypeck: (1) the number of trials prior to the first peck, (2) the number of trials prior to the first peck to occur during a trial, and (3) the number of trials prior to a sequence of four successive trials during which a peck occurred on at least three of these trials. The functions relating the value of the ITI duration to the number of trials needed to satisfy each of these criteria were essentially indistinguisinable. In 47

Table 1

Experimental Conditions

\begin{tabular}{|c|c|c|c|c|c|c|c|c|c|}
\hline $\begin{array}{l}\text { Group } \\
\text { Number }\end{array}$ & $\begin{array}{c}\text { ITI } \\
\text { Value } \\
(\mathrm{Sec}) \\
\end{array}$ & $\begin{array}{c}\text { Minimum } \\
\text { ITI } \\
(\mathrm{Sec})\end{array}$ & $\begin{array}{c}\text { Maximum } \\
\text { ITI } \\
(\mathrm{Sec})\end{array}$ & $\begin{array}{l}\text { Experiment } \\
\text { Conducted } \\
\text { in Box No. }\end{array}$ & $\begin{array}{l}\mathrm{N} \\
\text { Acqui- } \\
\text { sition }\end{array}$ & $\begin{array}{l}\mathrm{N} \\
\text { Mainte- } \\
\text { nance }\end{array}$ & $\begin{array}{l}\text { Maximum } \\
\text { Eating } \\
\text { Duration } \\
\text { (Sec) }\end{array}$ & $\begin{array}{l}\text { Sessions } \\
\text { Conducted }\end{array}$ & $\begin{array}{c}\text { Number of } \\
\text { Maintenance } \\
\text { Sessions }\end{array}$ \\
\hline \multicolumn{10}{|c|}{ Experiment I } \\
\hline 1 & 5 & 0.5 & 19 & 2 & 1 of 4 & 0 & 4.0 & Daily & 0 \\
\hline 2 & 10 & 0.5 & 38 & 2 & 4 & 4 & 4.0 & Daily & 11 \\
\hline 3 & 12 & 0.5 & 90 & 1 & 7 of 8 & 7 & 3.5 & Daily & 7 \\
\hline 4 & 18 & 1.0 & 88.5 & 2 & 7 & 4 & 4.0 & Daily & 11 \\
\hline 5 & 30 & 1.0 & 147.5 & 2 & 4 & 4 & 4.0 & Daily & 11 \\
\hline 6 & 37 & 0.5 & 190 & 1 & 8 & 8 & 3.5 & Every Other Day & 11 \\
\hline 7 & 44 & 0.5 & 210 & 1 & 4 & 4 & 3.5 & Every Other Day & 11 \\
\hline 8 & 69 & 0.5 & 500 & 1 & 8 & 8 & 3.5 & Every Other Day & 11 \\
\hline 9 & 100 & 2.0 & 491 & 2 & 8 & 4 & 4.0 & Daily & 11 \\
\hline 10 & 150 & 6.0 & 572 & 2 & 4 & 4 & 4.0 & Daily & 11 \\
\hline 11 & 250 & 2.5 & 1228 & 2 & 8 & 4 & 4.0 & Daily & 11 \\
\hline 12 & 400 & 16.0 & 1527 & 2 & 4 & 4 & 4.0 & Daily & 11 \\
\hline \multicolumn{10}{|c|}{ Experiment II } \\
\hline 1 & 11 & 0.5 & 100 & 1 & 8 & 8 & 3.5 & Daily & 11 \\
\hline 2 & 13 & 0.5 & 90 & 1 & 4 of 8 & 4 & 3.5 & Daily & 7 \\
\hline 3 & 16 & 0.5 & 130 & 1 & 9 & 9 & 3.5 & Every Other Day & 11 \\
\hline 4 & 26 & 0.5 & 170 & 1 & 9 & 9 & 3.5 & Every Other Day & 11 \\
\hline 5 & 40 & 0.5 & 200 & 1 & 8 & 8 & 3.5 & Daily & 11 \\
\hline 6 & 66 & 0.5 & 450 & 1 & 8 & 8 & 3.5 & Every Other Day & 11 \\
\hline 7 & 164 & 0.5 & 1340 & 1 & 6 & 0 & 3.5 & Every Other Day & 0 \\
\hline 8 & 246 & 0.5 & 1260 & 1 & 2 & 0 & 3.5 & Every Other Day & 0 \\
\hline
\end{tabular}


out of 68 instances, the first peck occurred during a trial, and this first peck was followed reliably by pecks on subsequent trials.

The left-hand panel of Fig. 1 shows the number of trials prior to the first peck during an S1 trial as a function of the mean ITI interval. Note that boti coordinates of Fig. 1 are logarithmic. The left-hand function of Fig. 1 shows that the mean duration of the ITI exerts a powerful influence on the acquisition of the keypeck. The median number of trials prior to the first peck during an S1 trial approximated a power function with an exponent of -0.57 and covered a range of more than one log unit. Data from the 5-sec group have been omitted from this and from subsequent analyses, since only one of tive four Ss of this group pecked during the 11 autoshaping sessions to which they were exposed. The $\mathrm{S}$ whicil did peck emitted its first peck during the ITI following the 272nd S1 trial (Session 11). The data from Brown and Jenkins's (1968) and from Engberg et al's (1972) studies, both of which used an 8-sec trial, fall very close to our function. Differences in eating time, in the methods used to generate the intertrial intervals, as well as in the laboratory in which the data are obtained, do not appear to irave influenced tine shape of the acquisition function.

One difference between the data obtained from Boxes 1 and 2 is the somewhat larger ranges of the Box 1 data. This difference may reflect the broader range of intervals (noted earlier) used in Box 1. If, by chance, some of the Box 1 Ss were exposed to a sequence of short ITIs, their acquisition may have been retarded. Likewise, the acquisition of some of the Box 1 Ss may have been facilitated if they were initially exposed to a sequence of short ITIs. This could account for agreement of the medians of the Box 1 and Box 2 points and, at the same time, explain the larger ranges for the Box 1 points. Whatever the contribution of the range of intervals, it is impressive to note that the correlation coefficient between the value of the $\log$ of mean ITI and the $\log$ of median number of trials to criterion was -0.97 .

Steady State Performance. Mean running rates of responding to $\mathrm{S} 1$ of each group during the sessions that followed the first acquisition session are shown in Fig. 2 . Running rates were caluclated as follows: The total number of responses to S1 during each session was divided by the cumulated time in S1 that elapsed after the first response on any trial. In order to separate visually the different experimental groups, two sets of rate functions are shown in Fig. 2. The right-hand panel shows the rate functions obtained from the long ITI groups $(69-400 \mathrm{sec})$.

The functions shown in Fig. 2 indicate that initial and terminal rates of pecking varied directly with the duration of the ITI. A two-way analysis of variance (ITI Value by Sessions) yielded a significant ITI and sessions effects, as well as a significant interaction (ITI: F-ratio $=2.5 ; \mathrm{df}=9 / 30 ; \mathrm{p}<.05 ;$ sessions: F-ratio $=2.8 ;$ $\mathrm{df}=10 / 90 ; \quad p<.01 ; \quad$ interaction: $\quad F$-ratio $=1.4$; $\mathrm{df}=90 / 300 ; p<.01)$. The ITI and the sessions effects corroborate what is apparent from visual inspection of Fig. 2. The significant interaction indicates tnat the slopes of the short ITI functions are steeper tilan those of the long ITI functions. Indeed, for long ITIs, there seems to be some terminal reduction in rate as training continues. In view of such data, it seems foolinardy to suppose that 11 sessions are sufficient to provide a stable picture of steady state performance. As insensitive as the pigeon's keypeck may appear to contingencies (cf. Williams \& Williams, 1969; Herrnstein \& Loveland, 1972), it may be that the absence of a contingency results in a gradual lowering of response rates (cf. right-hand panel of Fig. 2).

A summary function of each group's running rates during the last three maintenance sessions, along with
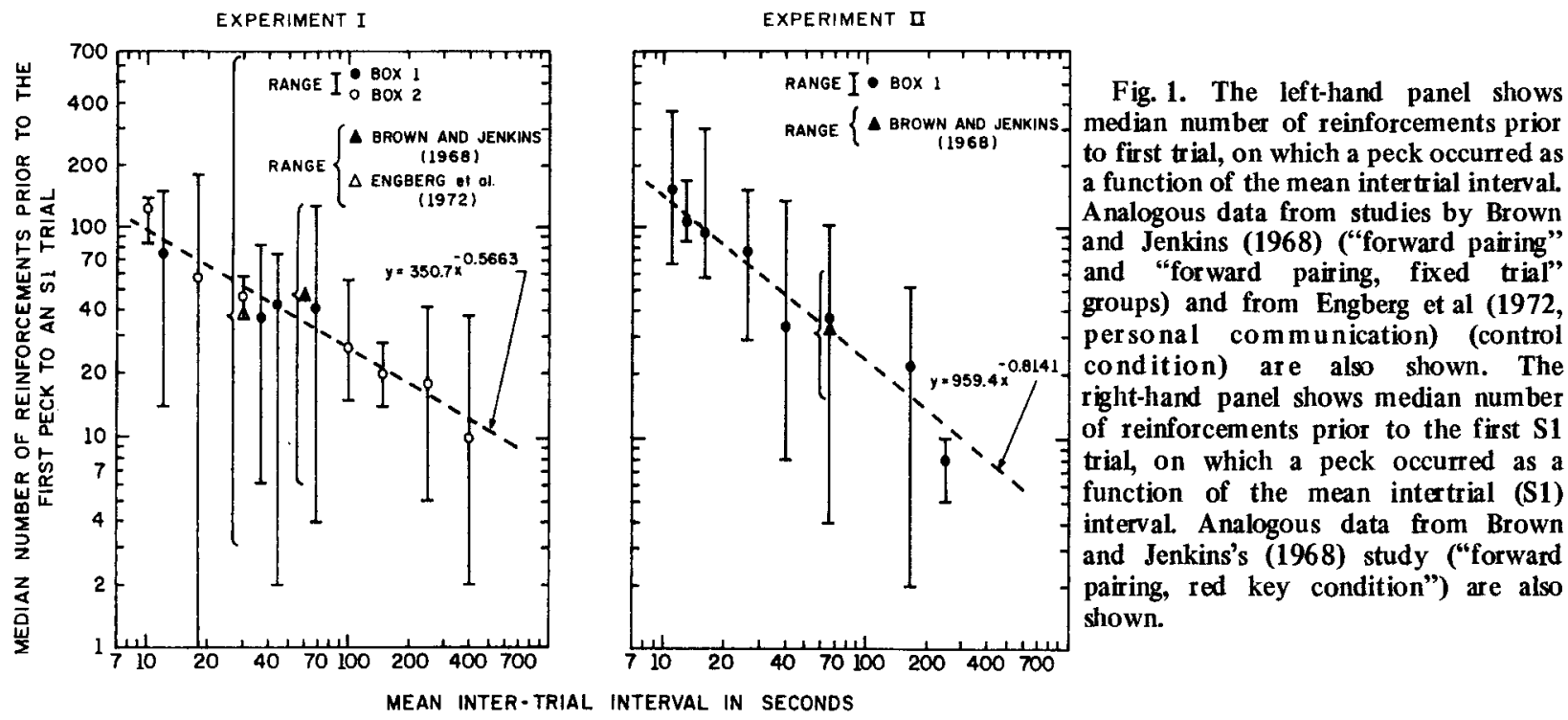


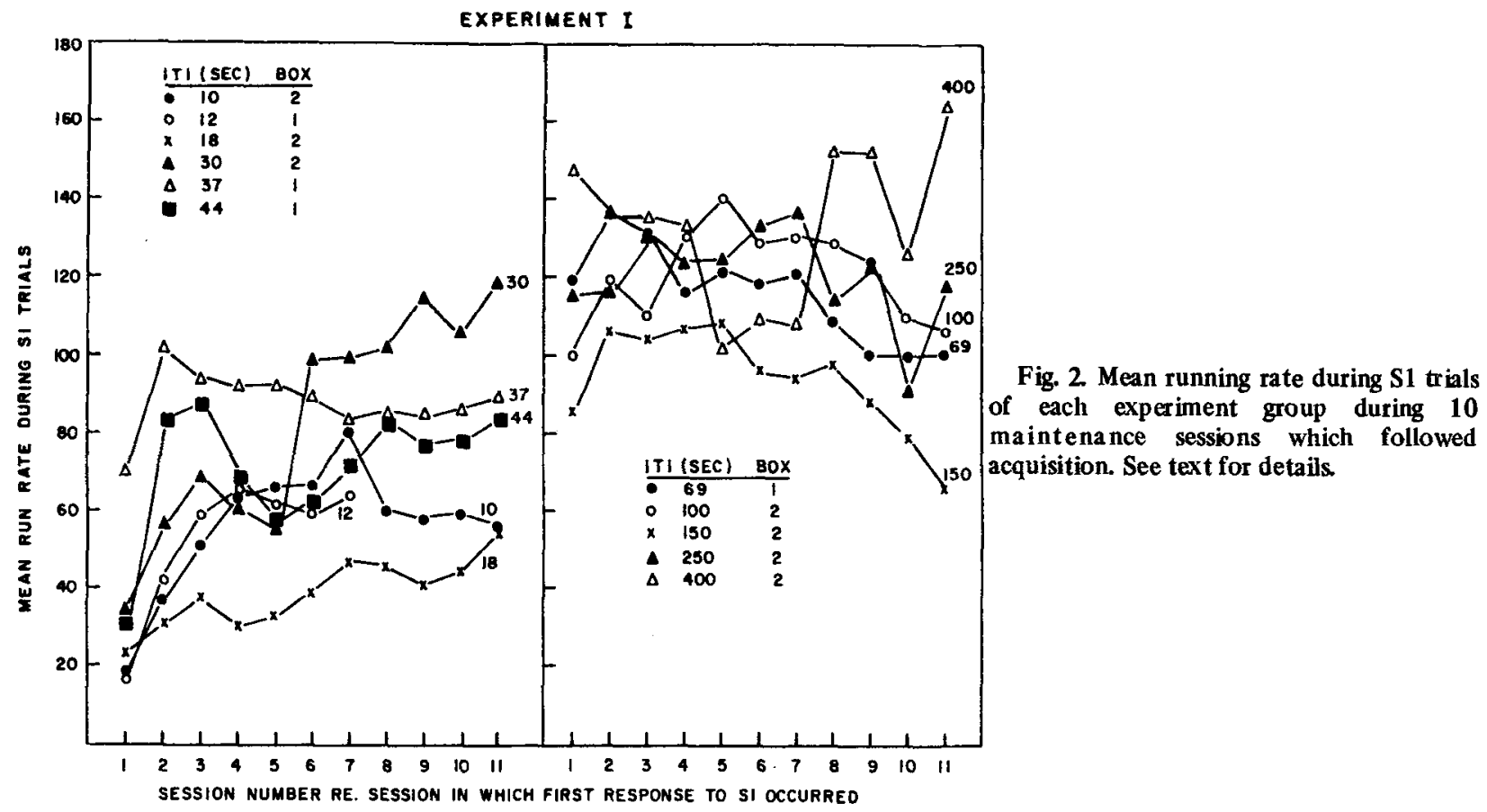

their standard deviations, are shown on $\log -\log$ coordinates in Fig. 3. Terminal running rates vary as a power function of the intertrial interval, with a relatively low exponent. The power function shown in Fig. 3 may prove significant in describing the relationship between rate of acquisition and the ultimate strength of a conditioned response. All of the Ss pecked at relatively high rates. Yet, the rate of pecking of those Ss which autoshaped most rapidly (the long ITI Ss) tended to be the most rapid. As was true of the acquisition function (Fig. 1, left-hand panel), the ITI variable accounts for a high proportion of variance (approximately 60\%). It should be noted, however, that the ITI variable accounted for less of the variance of the terminal-rate function than it did in the case of the acquisition function (60\% vs $94 \%)$.

Another measure of responding is the probability of pecking at least once during each presentation of S1. The relevant data are shown in Fig. 4. Following acquisition of the keypeck, the tendency to peck at least once during subsequent presentations of $\mathrm{S} 1$ approaches asymptotic values by about the third maintenance session. Even after 11 maintenance sessions, the probability of at least one response during each $S 1$ trial did not approach 1.0 for all groups (e.g., 10. 18- and 44-sec groups). A two-way analysis of variance revealed that the session effect was highly significant $(F=38.2$; $\mathrm{df}=9 / 30 ; p<.01)$. Neither the ITI effect nor the interaction were significant.

\section{EXPERIMENT II}

Method

Subjects and Apparatus. The Ss were 60 male White Carneaux pigeons which ranged in age from 6 months to 1 year. All of the Ss were experimentally naive. The apparatus consisted of

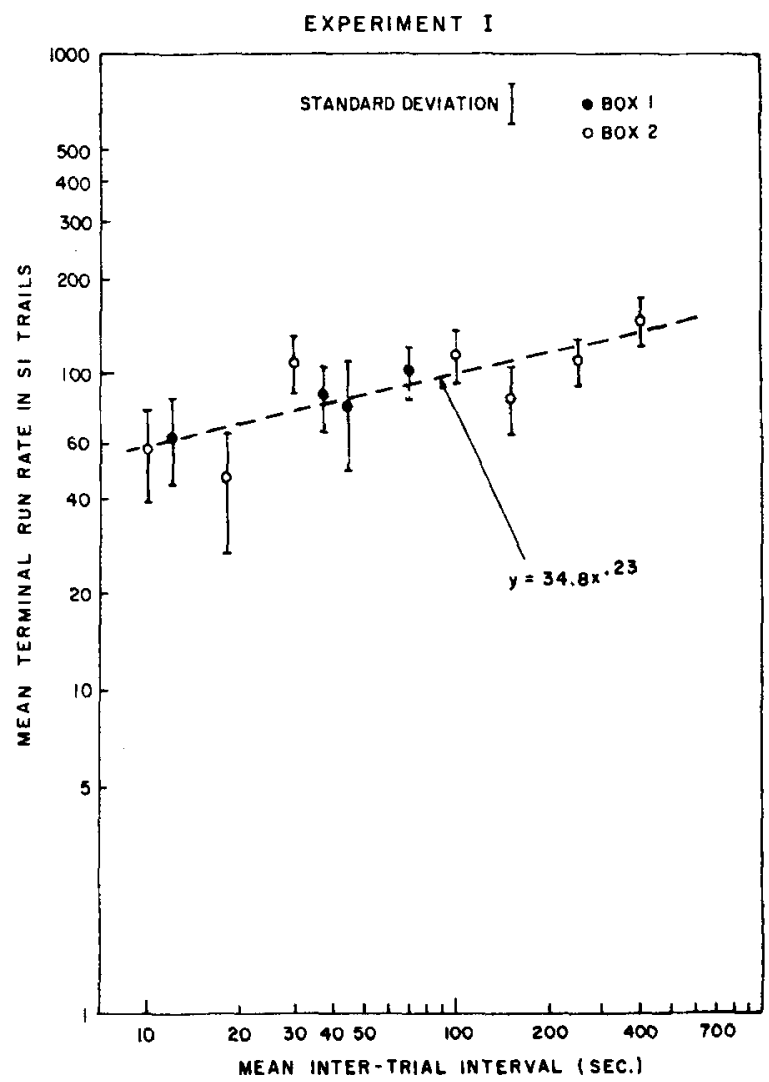

Fig. 3. Mean running rate during last session, and standard deviations, during S1 trials of each experimental group as a function of mean intertrial interval. 


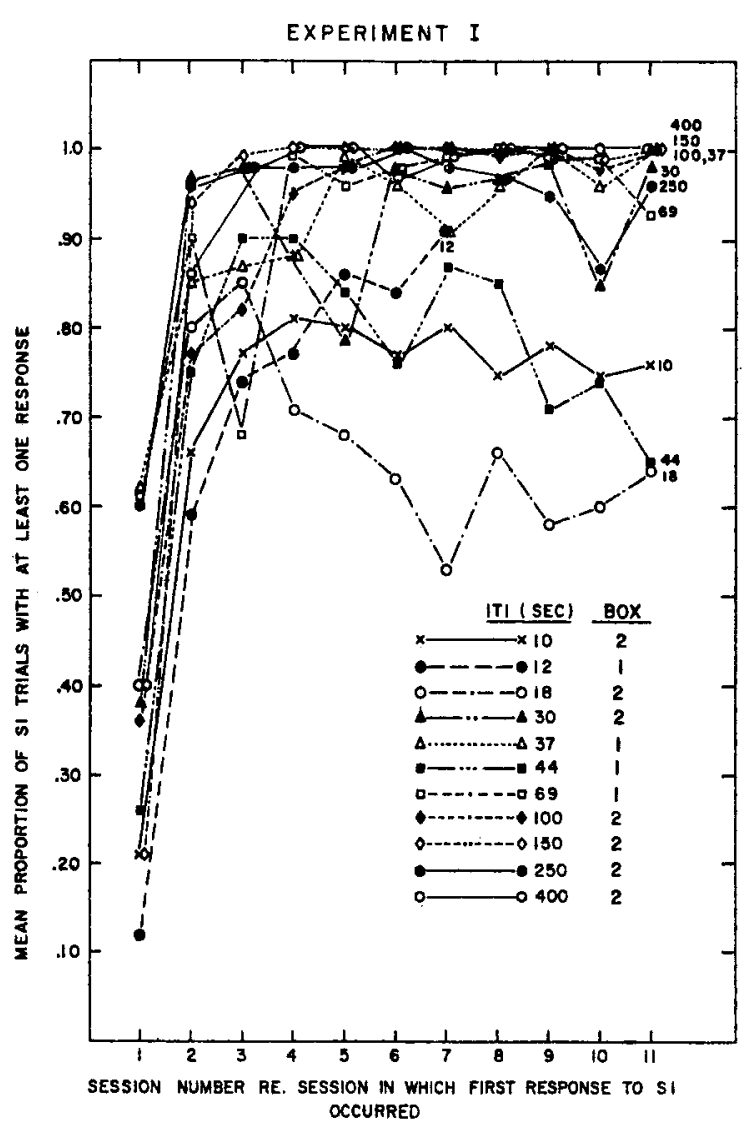

Fig. 4. The probability of at least one response during each S1 trial of each experimental group during the 10 maintenance sessions which followed the first keypeck.

Experimental Chamber 1 and related programming equipment used in Experiment $\mathrm{I}$.

In Experiment II, S1 and S2 were alternated successively in an irregular series. S1, a green light, was always followed by food. Its luminance was the same as the luminance of $\mathrm{S} 1$ of Experiment I. S2, a red light, was never followed by food. The luminance of $S 2$ was $-0.85 \log \mathrm{fL}$. Except for the addition of S2, the procedure of Experiment II was identical to that followed in Box 1 of Experiment $\mathrm{I}$.

The durations of S1 and S2 were each $10 \mathrm{sec}$. Following both kinds of trial, there was a $1 / 2-\mathrm{sec}$ period during which no stimulus appeared on the key. Thus, the intervals between $S 1$ presentations were filled with S2 presentations, except for the $0.5-\mathrm{sec}$ dark period between trials. If, for example, the interval between $\mathrm{S} 1$ onsets was programmed to be $35 \mathrm{sec}$, two $\mathrm{S} 2$ trials appeared between successive $\mathrm{S} 1$ presentations. The actual sequence would consist of the following events: $\mathbf{S} 1(10 \mathrm{sec}), \mathbf{S}^{\mathbf{R}}$ $(3.5 \mathrm{sec})$, dark key $(0.5 \mathrm{sec}), \mathrm{S} 2(10 \mathrm{sec})$, dark key $(0.5 \mathrm{sec}), \mathrm{S} 2$ $(10 \mathrm{sec})$, dark key $(0.5 \mathrm{sec})$, and then the onset of S1.

In Experiment II, the values of the intertrial interval were determined by the probability generator method described earlier, except that now $10 \mathrm{sec}$ of each 10.5 -sec dark interval of Experiment I was occupied by a red trial. These and other aspects of the procedure of Experiment II are summarized in the bottom portion of Table 1. Table 1 also notes occasional exceptions to our plan for conducting ten maintenance sessions following acquisition of the keypeck. In our description of the results, maintenance data are presented only for Ss that completed at least 7 sessions of the 10 -session program.

\section{Results}

Acquisition. The main results of Experiment II are shown in the right-hand panel of Fig. 1. The same criteria used to analyze the acquisition of keypecking in the first experiment were applied to the results of our second experiment. Again, the functions generated by each of these criteria were similar. Of the 46 Ss which satisfied the criterion of responding on at least three of four successive positive trials, the first response of 31 of these Ss was to $\mathrm{Sl}$. Of the 15 Ss whose first response did not occur on an S1 trial, 13 of these responses occurred to $\mathrm{S} 2$ and 2 of these responses occurred during the 0.5 -sec dark period. Even though almost one-third of the first pecks of those Ss winich eventually satisfied the three out of four S1 trial criterion occurred during an S2 trial, these Ss soon began to peck at $\mathrm{S} 1$ and decreased their pecking to $\mathrm{S} 2$.

On $\log -\log$ coordinates, a linear relationship between ITI duration and the median number of reinforcements prior to the first $S 1$ peck accounts for a large portion of the variance of the medians $\left(\mathrm{r}^{2}=0.938\right)$. Thus, as in Experiment $\mathrm{I}$, a power function appears to describe the relationship between ITI and trials to criterion. The value of the slope obtained in Experiment II was -0.81 . This slope was significantly steeper than the slope of the Experiment I function $(t=2.7 ; \mathrm{df}=15$; $\mathrm{p}<.02$ ). The difference between the slopes of the acquisition functions of Experiments I and II appears to result primarily from the retardation in Experiment II at short ITI values.

Maintenance. In most respects, the rate and probability data obtained in Experiment II are similar to those of Experiment I.

Pecks to S1 Mean running rates of responding to S1 of each group are shown in Fig. 5. As was the case in Experiment 1 , running rates vary directly with the value of the ITI. These data parallel those of Experiment I (cf. Fig. 2) with the exception that, at longer ITIs, the decrement over 11 sessions was less pronounced in Experiment II than in Experiment I. An analysis of variance showed that both the main effects (ITI and sessions) as well as the interaction were highly significant (ITI: $F=6.7$; $\mathrm{df}=4 / 35 ; \mathrm{p}<.01 ;$ sessions: $\mathrm{F}=28.2 ; \mathrm{df}=10 / 40 ; \mathrm{p}<.01 ;$ interaction: $F=2.635 ; \mathrm{df}=40 / 350 ; \mathrm{p}<.01$ ).

A summary function of the mean running rates of the last three sessions and their standard deviations are shown on $\log -\log$ coordinates in Fig. 6. As in Experiment I, terminal rate of pecking varies as a power function of the intertrial interval. A correlation coefficient of 0.73 was obtained between the values of the $\log$ of the mean ITI and that of the $\log$ of the mean terminal running rate.

A comparison of the slopes of the functions shown in Figs. 3 and 6 suggests that rate of pecking to $S 1$ rises somewhat more rapidly as a function of ITI duration in Experiment II than in Experiment I. The difference between the slopes of these functions fell short of statistical significance. At least three other factors also limit comparisons of the slopes of the functions shown in Figs. 3 and 6: (1) The range of ITI durations covered in Experiment I $(10-400 \mathrm{sec})$ was greater than that covered in Experiment II $(11-246 \mathrm{sec})$. (2) Higher rates in S2 can be observed systematically only at ITI durations greater than $12 \mathrm{sec}$. (3) The rate at $37 \mathrm{sec}$ in the Experiment I function is higher than the rates of responding at two adjacent ITI values on the Experiment II function (26 and $40 \mathrm{sec}$ ). We will later argue that the higher rates of responding obtained in Experiment II may prove to be an example of behavioral contrast. Behavioral contrast might be expected to occur in Experiment II since S1, which was always followed by reinforcement, was alternated with S2, which was never followed by reinforcement. 


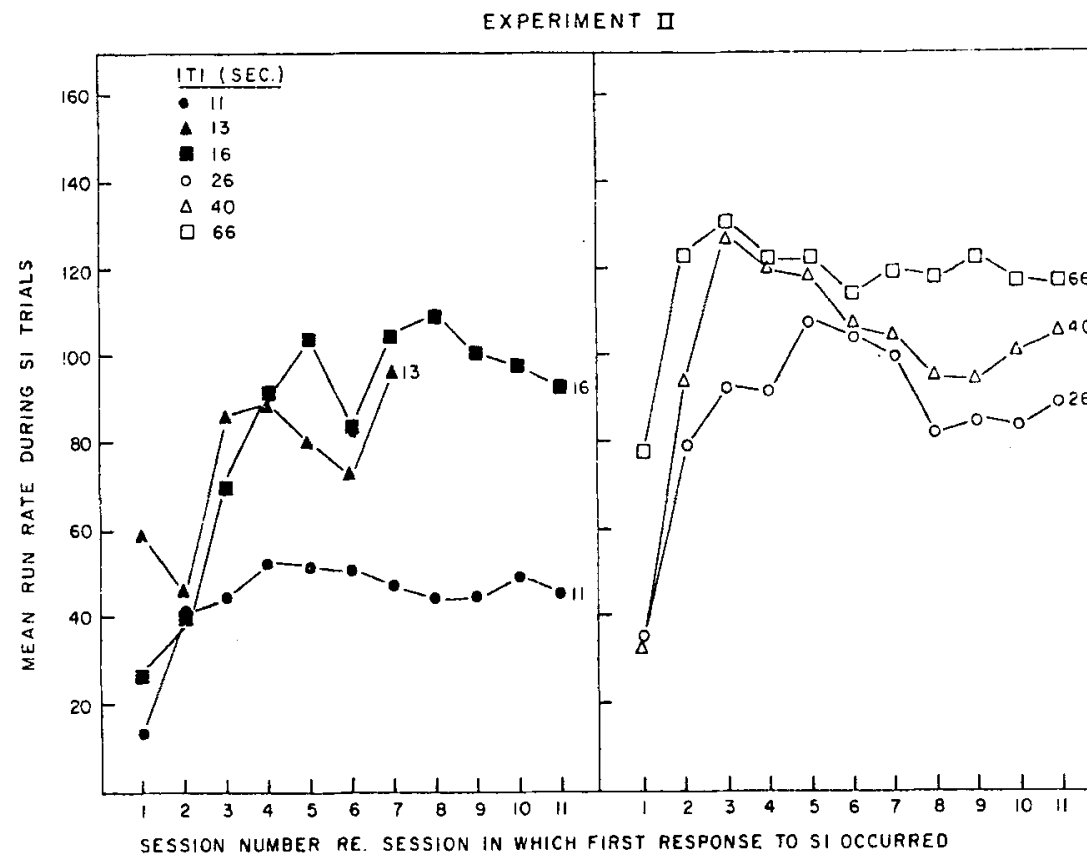

Fig. 5. Mean running rate during S1 trials of each experimental group of Experiment II during the 10 maintenance sessions which followed first keypeck.

The probability of responding at least once during each presentation of $\mathrm{S} 1$ increased during successive maintenance sessions. As shown in Fig. 7, the terminal probability of responding was lowest for the short ITI groups. In the case of the $11-\mathrm{sec}$ group, the mean probability of making at least one

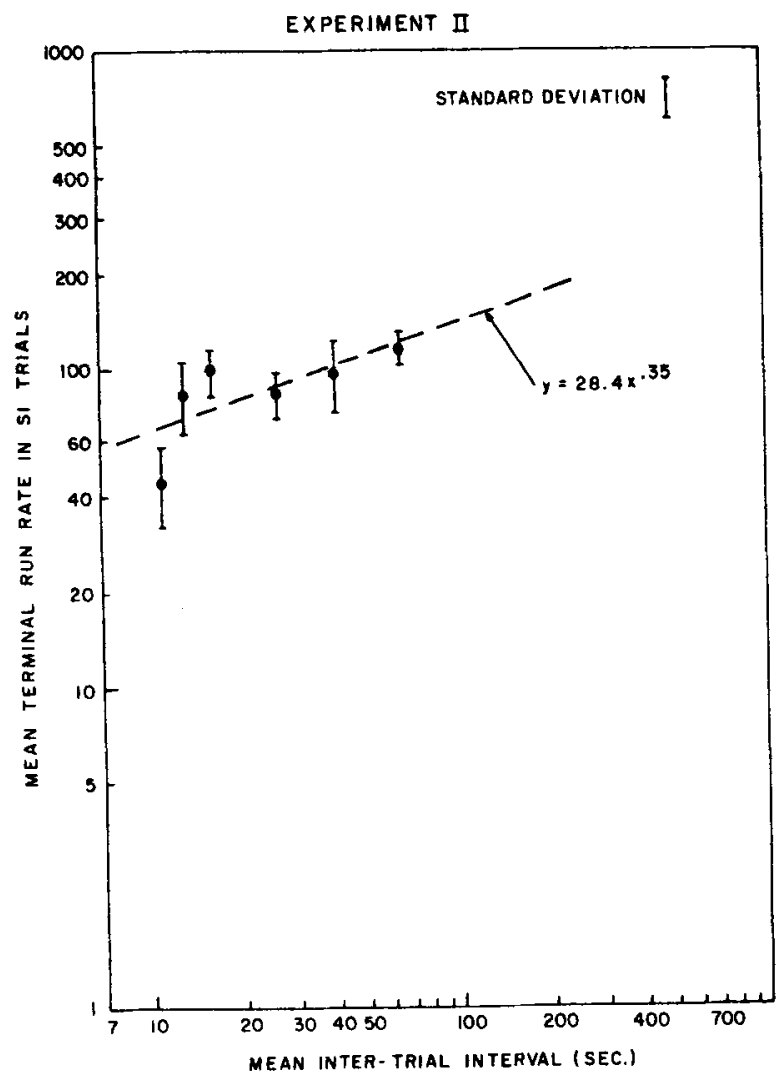

Fig. 6. Mean running rate during last session, and standard deviations, during $S 1$ trials of each experimental group as a function of intertrial interval.

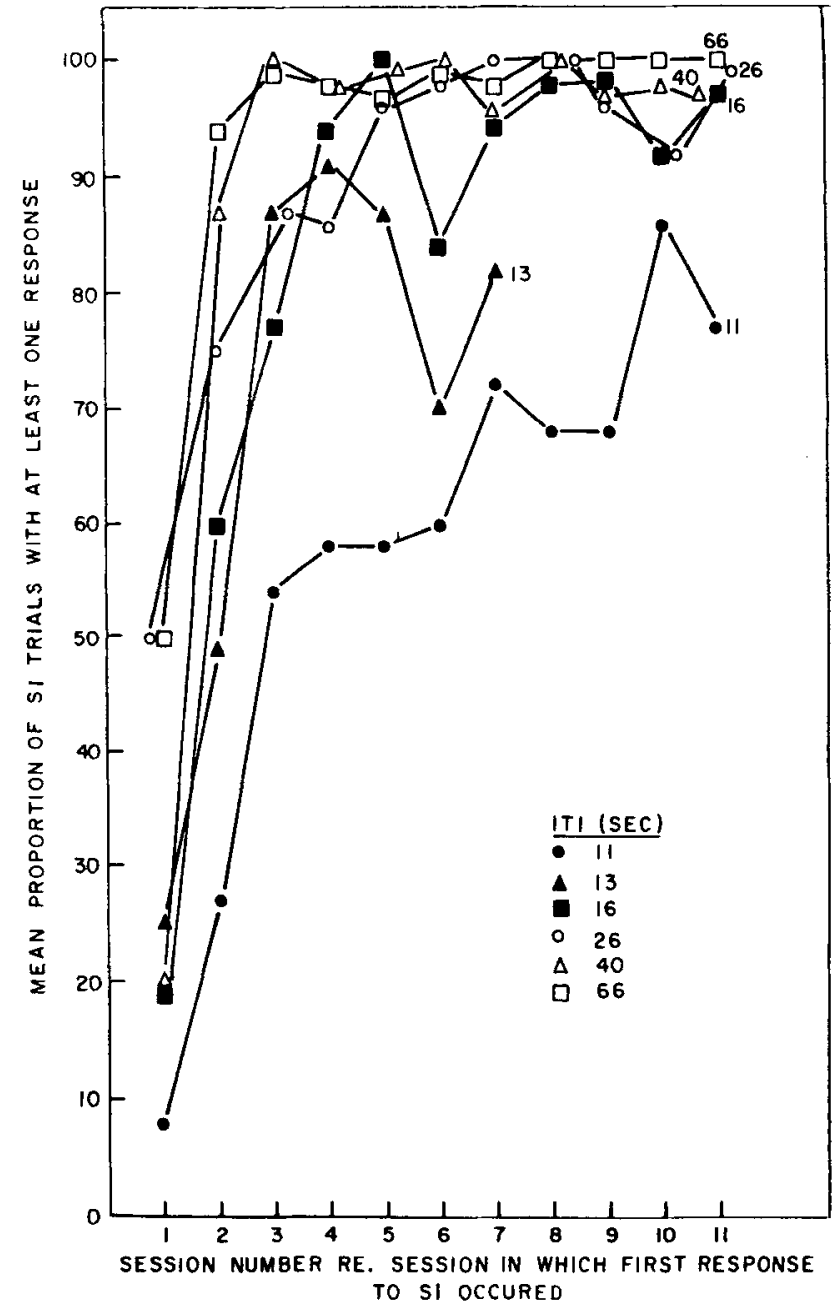

Fig. 7. Probability of at least one response during an S1 trial of each experimental group during the maintenance sessions which followed first keypeck. 


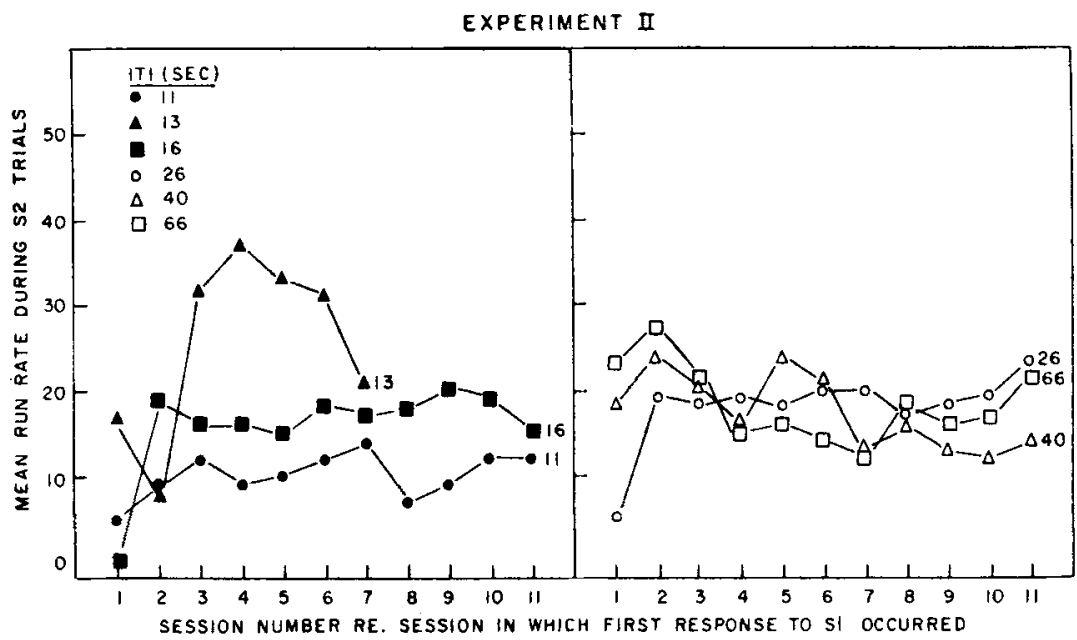

Fig. 8. Mean running rate during $S 2$ trials of each experimental group in Experiment II during each of the 10 maintenance sessions which followed acquisition of the keypeck.

response to each presentation of $S 1$ exceeded a value of 0.8 only once (during Session 10). A two-way analysis of variance of ITI and session effects revealed that both main effects were highly significant. The interaction was not (ITI: $F=9.2, \mathrm{df}=4 / 35$, $\mathrm{p}<.01$; sessions: $\mathrm{F}=52.5, \mathrm{df}=10 / 40, \mathrm{p}<.01)$. The probability of responding at least once in $S 1$ increased more gradually in Experiment II over sessions than in Experiment I (cf. Fig. 3). In Experiment I, response probability generally peaked within three sessions of the first peck.

Despite small differences in the rates and the probabilities of responding to $S 1$ in Experiments I and II, the results of both experiments demonstrate that ITI duration exerts a powerful influence on whether or not a peck will occur well beyond the trial on which pecks first occur.

Pecks to S2. All of the Ss of each of the ITI groups responded to S2. As indicated earlier, most of the Ss responded to $S 1$ prior to the first response to $S 2$. However, responding to $S 2$ occurred in all groups, albeit at low rates, irrespective of whether the first response was to this stimulus. Figure 8 shows each group's running rates of responding in $\mathrm{S} 2$ during maintenance training. All groups pecked at a low rate in the range of approximately 10-25 responses $/ \mathrm{min}$. These rates are approximately one-fifth to one-tenth of the rates occasioned by S1 (cf. Figs.2 and 5). A two-way analysis of variance (ITI by Sessions) yielded nonsignificant main effects and a nonsignificant interaction. Thus, while $\$ 2$ rates are clearly above zero, they are not affected systematically either by ITI duration or by amount of training.

While rate of pecking to $\mathrm{S} 2$ did not vary substantially as a function of either ITI or number of sessions beyond the first peck, the probability of responding at least once to each S2 did increase gradually during the 11 maintenance sessions. These data are summarized in Fig. 9. A two-way analysis of the effects of ITI and sessions revealed significant main effects and a nonsignificant interaction (ITI: $F=3.7$, df $=4 / 35, p<.05$;
Fig. 9. Probability of at least one response during each $S 2$ trial of each experimental group in Experiment II during the $\mathbf{1 0}$ maintenance sessions which followed the first keypeck.

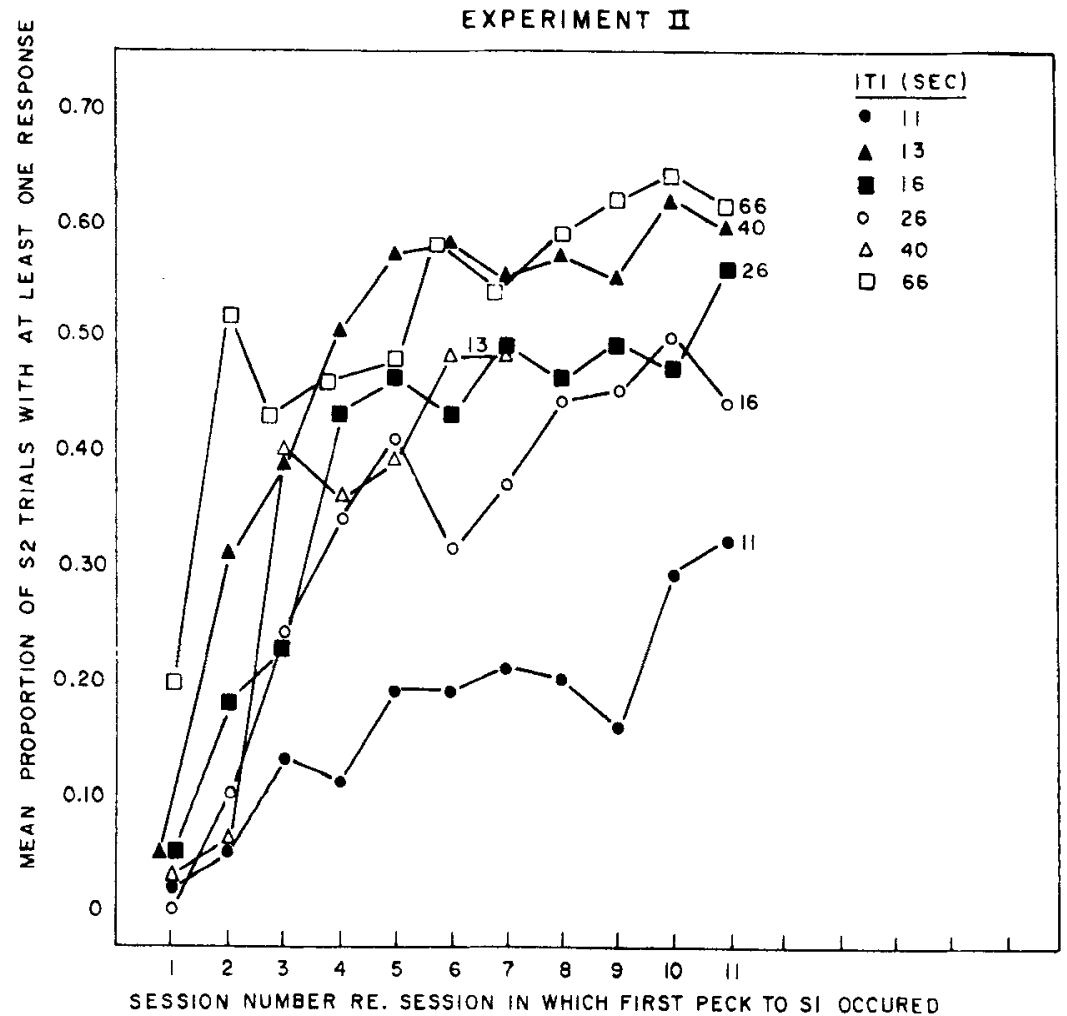


sessions: $\mathrm{F}=30.6, \mathrm{df}=10 / 40, \mathrm{p}<.001$ ). These results paralleled those for $\mathrm{S} 1$ pecking. Response probability in $\mathrm{S} 2$ increased as the duration of the ITI increased.

\section{DISCUSSION}

Both the acquisition and the subsequent performance of an autoshaped keypeck are strongly influenced by the duration of the ITI. These effects will be considered separately in the discussion that follows. In either case, the reader should keep in mind that ITI duration is but one of a variety of interesting and obvious parameters which could influence the acquisition and the subsequent occurrence of autoshaped keypecks. Other parameters include the probability of reinforcement and the relative values of trial and intertrial interval durations. At present, it is not clear what influence such parameters might exert on the acquisition of an autoshaped response (parameters which were kept constant in the present study). Our analysis of the effects of ITI duration must be considered tentative.

\section{Acquisition}

Intertrial-interval functions have enjoyed widespread discussion in the literature on massed vs distributed practice (cf. Kimble, 1961) and have been cited as examples of the effect of "reactive inhibition" (cf. Hull, 1943; Gormezano \& Moore, 1969, pp. 146-148). The concept of reactive inhibition is not, however, helpful in interpreting the present data, even if one infers an "orienting" or "attention-like" process which intervenes prior to the development of the keypeck. The main empirical basis for asserting that increases in ITI duration facilitate the acquisition of a conditioned response is the literature on the classically conditioned eyelid response (e.g., Humphreys, 1941; Spence \& Norris, 1950; Prokasy, Grant, \& Myers, 1958). The range of ITI durations of the present functions is considerably larger than that encountered in studies of the conditioned eyeblink. It is, therefore, unlikely that our acquisition data have very much to do with differences in the reactive inhibition of an attention response as accruing during intertrial intervals of, say, 100 and $400 \mathrm{sec}$.

The possibility that the keypeck emerges from orienting behavior has been discussed explicitly by Browll and Jenkins (1968). They argued that orienting responses and/or attention may precede the establishment of an autoshaped response. It is not obvious to us how the ITI effect we report might fit into such a view. Possibly one might regard attention as being recruited more strongly to a rare rather than a frequent signal, but such a view does little more than restate the phenomenon.

An alternative view derives from an associational model developed by Gibbon et al (1974). This model attempts to assess the perceived correlation between the signal and food and regards rare signals as providing more information about food than frequent signals. A basic assumption underlying this characterization is that the perceived probability of reinforcement during a trial is less than unity. That is, Ss are regarded as discriminating early unreinforced portions of the signal from later reinforced portions, and thus the overall predictability of food from the signal is less than perfect. With this assumption, it may be shown that increasing ITI durations results in increasing the correlation between positive trials and food. Hence, increases in perceived association might be regarded as responsible for our ITI effect.

Another association model that would predict an inverse relationship between trials to acquisition and ITI duration is Rescorla and Wagner's (1972) model of the associational value of compound stimuli. This model regards the intertrial interval as the background stimulus (A) which is alternated with the trial stimulus (AX). Thus, the longer the intertrial interval, the greater the frequency of $\mathbf{A}$ trials (on which reinforcement is absent). The critical assumption of the Rescorla-Wagner model is that the greater frequency of A-alone periods (the longer the ITI), the lower the associational value of $A$, and the greater the increment in $\mathrm{X}$ on an $\mathrm{AX}$ trial. The Rescorla-Wagner model has not specified a means of translating the associational value of $\mathrm{X}$ into some response metric. If, however, one assumes that the associational value of $\mathrm{X}$ is proportional to the number of trials to acquisition, the Rescorla-Wagner model does predict an inverse relationship between trials to acquisition and ITI duration. But, as is also the case with Gibbon et al's analysis, it cannot account for the negative power function shown in Fig. 1.

Neither the attentional approach nor the association view explicitly handles the retardation we observed when an additional negative trial signal "fills" the ITI. Possibly the greater contrast between a lit vs a dark key in Experiment I adds a salience dimension which facilitates conditioning. Alternatively, generalization between signal onsets, both positive and negative, may retard autoshaped pecking.

In Experiment II, some of the Ss' initial responses occurred during S2 trials, and all of the Ss responded extensively to S2. An interesting problem for further study is what variables determine whether responding to S2 occurs and with what frequency. Wessels (1973) and Wilkie (1973) have recently reported errorless acquisition of a discrimination with the autoshaping paradigm. These experiments differed from Experiment II of the present study in two important respects. They used different discriminative stimuli, and S2 was presented less frequently and at shorter durations. At present, there is no basis for determining the extent to which these factors are crucial for the errorless acquisition of discrimination during autoshaping. 
In general, our acquisition and performance data covary in that rapid acquisition is associated with high rates, and probabilities of responding to $\mathrm{S} 1$. Superficially, the strong correlation between rate of acquisition and level of asymptotic performance is grist for the mill of a response-strength theorist. Both of our measures of response strength (rate and probability of pecking) covary in a manner required by the concept of response strength (cf. Hull, 1943). There are, however, at least two compelling arguments against the interpretation of our data as evidence of a necessary relationship between rate of acquisition and level of performance. One is the absence of data on the effects of other parametric manipulations. Of particular interest is the influence of intermittent reinforcement on the measures studied in the present experiment. In the instrumental conditioning literature, intermittent reinforcement remains the main stumbling block for attempts to relate measures of response strength to frequency of reinforcement. It would not be surprising to see similar discrepancies between measures of performance and frequency of reinforcement in studies employing an autoshaping paradigm. The little data presently available (Gonzales, 1973; Winokur \& Frank, 1973; Farrell \& Terrace, 1974) does not allow any clear conclusions to be drawn about the effect of intermittent reinforcement on the acquisition of an autoshaped response.

Another complication in the interpretation of the S2 data is that these relationships may prove to be examples of behavioral contrast. Aside from the effects of intermittent reinforcement, behavioral contrast is another widely observed phenomenon that makes it difficult for a Hullian theory of reinforcement to relate response strength to frequency of reinforcement. Evidence of behavioral contrast can be seen by comparing our terminal rate functions with those obtained from experiments performed by Taus and Hearst (1970), Vieth and Rilling (1972), Sadowsky (1973), and Terrace (1963). Taus and Hearst varied the duration of a blackout interval between presentations of a stimulus in the presence of which responses were reinforced on a variable interval (VI) schedule of reinforcement. They reported that rate of responding to the stimulus correlated with VI reinforcement increased as the duration of the ITI increased (over a range from 0 to $30 \mathrm{sec}$ ). Taus and Hearst suggested that their results were a contrast phenomenon resulting from a reduction in relative frequency of reinforcement. Such results may also be attributed to the aversiveness of timeout (cf. Terrace, 1974). That possibility is not as much of interest to the present discussion as the possibility that the functions relating ITI duration and response rate are more a measure of contrast than a manifestation of the rapidity of acquisition. One wonders, for example, if the rate of an $S$ initially trained at a short ITI would increase when it was shifted to a longer ITI. One way to factor out the influence of rate of acquisition is to vary ITI duration within groups over a range comparable to that used in the between-groups design of the present experiment

The terminal rate function of Experiment II is slightly (but not significantly) steeper than that of Experiment I (cf. Figs. 4 and 6). Unfortunately, the shorter range of ITI values of Experiment II does not permit as exhaustive a comparison with the analogous function obtained in Experiment I as one might desire. It is interesting to note, however, that the addition of $\mathrm{S} 2$, a stimulus never followed by reinforcement, results in an increase in the rate of responding to $\mathrm{Sl}$. The same effect has been observed in many experiments on discrimination learning (cf. Terrace, 1966).

\section{REFERENCES}

Bolles, R. C. Reinforcement, expectancy, and learning Psychological Review, 1972, 79, 394-409.

Brown. P. L., \& Jenkins, H. M. Auto-shaping of the pigeon's key-peck. Journal of the Experimental Analysis of Behavior, $1968,11,18$

Catania, A. C., \& Reynolds, G. S. A quantitative analysis of the responding maintained by interval schedules of reinforcement. Journal of the Experimental Analysis of Behavior, 1968, 11, 327-383

Engberg, L. A., Hanse, G., Welber, R., \& Thomas, D. R. Acquisition of key pecking via autoshaping as a function of prior experience: "Learned laziness"? Science, 1972, 178, 1002-1004.

Farrell, L., \& Terrace, H. S. The role of partial reinforcement in the acquisition of an autoshaped response. Paper presented at Eastern Psychological Association, Philadelphía, Pennsylvania, April 1974.

Ferster, C.. \& Skinner, B. F. Schedules of reinforcement. New York: Appleton-Century-Crofts, 1957.

Gibbon, J. Berryman, R, \& Thompson, R. L. Contingency spaces and measures in classical and instrumental conditioning. Journal of the Experimental A nalysis of Behavior, 1974, 21 , $42-62$.

Gormezano, I., \& Moore, J. W. Classical Conditioning, In M, H. Marx (Ed.), Learning: Processes. London: MacMillan, 1969. Pp. $121-203$.

Gonzales, F. A. Effects of partial reinforcement (25\%) in an autoshaping procedure. Bulletin Psychonomic Society, 1973, 2, 299-301.

Hearst, E., \& Jenkins, H. M. Sign-tracking: The stimulus reinforcer relation and directed action. Austin, Texas: Psychonomic Society, 1974.

Herrnstein, R., \& Loveland, D. H. Food avoidance in hungry pigeons and other perplexities. Journal of the Experimental Analysis of Behavior, $1972,18,366-383$.

Hull, C. L. Principles of behavior. New York: Appleton-Century-Crofts, 1943.

Humphreys, L. G. Extinction of conditioned psycho-galvanic responses following two conditions of reinforcement. Journal of Experimental Psychology, 1940, 27, 71-75.

Kimble, G. A. Hilgard and Marquis' conditioning and learning. New York: Appleton-Century-Crofts, 1961.

Peterson, G. B., Ackil, J. E., Frommer, G. P., \& Hearst, E. S. Conditioned approach and contact behavior towards signals for food or brain-stimulation reinforcement. Science, 1972 , $177,1009-1011$.

Prokasy, W. F., Grant, D. A., \& Myers, N. A. Eyelid conditioning as a function of unconditioned stimulus intensity and intertrial interval. Journal of Experimental Psychology, 1958, 55. 242-246.

Rescorla, R. A., \& Wagner, A. R. A theory of Pavlovian conditioning: Variations in the effectiveness of reinforcement and nonreinforcement. In A. H. Black and W. F. Prokasy (Eds.), Classical conditioning II: Current theory and research. New York: Appleton-Century-Crofts, 1972, 64-99.

Sadowsky, S. Behavioral contrast with timeout, blackout, or extinction as the negative condition. Journal of the Experimental Analysis of Behavior, 1973, 19, 499-507.

Segal, E. F. In R. M. Gilbert and J. R. Millenson (Eds.), Reinforcement: Behavioral analysis. New York: Academic Press, 1972, 1-34.

Seligman, M. E. P. \& Hager, J. Biological boundaries of learning. New York: Appleton-Century-Crofts, 1972. 
Spence, K. W., \& Norris, E. B. Eyelid conditioning as a function of the intertrial interval. Journal of Experimental Psychology, 1950, 40, 716-720.

Taus, S. E., \& Hearst, E. Effects of intertrial (blackout) duration on response rate to a positive stimulus. Psychonomic Science, $1970,19,265-267$.

Terrace, H. S. Errorless transfer of a discrimination across two continua. Journal of the Experimental Analysis of Behavior. $1963,6,223-232$.

Terrace, H. S. Stimulus Control. In W. K. Honig (Ed.), Operant behavior: Areas of research and application. New York: Appleton-Century-Crofts, 1966, 271-344.

Terrace, H. S. On the nature of non-responding in discrimination learning with and without errors. Journal of the Experimental Analysis of Behavior, 1974, 22, 6-14.

Vieth, A., \& Rilling, M. Comparison of tim eout and extinction as determinants of behavioral contrast: An analysis of sequential effects. Psychonomic Science, 1972, 27, 281-282.

Wessels, M. Errorless discrimination, autoshaping and conditioned inhibition. Science, 1973, 182, 941-943.

Wilkie, D. M. Autoshaping and errorless discrimination. Paper presented at the Psychonomic Society Meetings, November 1973.

Williams, D. R., \& Williams, H. Auto-maintenance in the pigeon: Sustained pecking despite contingent non-reinforcement. Journal of the Experimental Analysis of Behavior, 1969, 12, 511-520.

Winokur, S., \& Frank, A. Automaintenance of pigeon's keypecking on a variable ratio schedule of reinforcement. Paper read at the $14 \mathrm{th}$ annual Meeting of The Psychonomic Society, St. Louis, Missouri, November 1973.

Received for publication September 26, 1973; revision accepted July 18, 1974.) 